\title{
PERFORMANCE COMPARISON OF MOBILE AD HOC NETWORK ROUTING PROTOCOLS
}

\author{
Mandeep Kaur Gulati ${ }^{1}$ and Krishan Kumar $^{2}$ \\ ${ }^{1}$ Deptt. of Computer Science, KCW ASR, PTU Kapurthala, Punjab, India \\ ${ }^{2}$ Deptt.of Computer Science and Engg, SBS State Technical Campus Ferozepur, PTU \\ Kapurthala, Punjab, India
}

\begin{abstract}
Mobile Ad-hoc Network (MANET) is an infrastructure less and decentralized network which need a robust dynamic routing protocol. Many routing protocols for such networks have been proposed so far to find optimized routes from source to the destination and prominent among them are Dynamic Source Routing (DSR), Ad-hoc On Demand Distance Vector (AODV), and Destination-Sequenced Distance Vector (DSDV) routing protocols. The performance comparison of these protocols should be considered as the primary step towards the invention of a new routing protocol. This paper presents a performance comparison of proactive and reactive routing protocols DSDV, AODV and DSR based on QoS metrics (packet delivery ratio, average end-to-end delay, throughput, jitter), normalized routing overhead and normalized MAC overhead by using the NS-2 simulator. The performance comparison is conducted by varying mobility speed, number of nodes and data rate. The comparison results show that AODV performs optimally well not the best among all the studied protocols.
\end{abstract}

\section{KEYWORDS}

Mobile Ad hoc Network (MANET), AODV, DSDV, DSR

\section{INTRODUCTION}

A Mobile Ad hoc Network (MANET) is a collection of mobile platforms that form a dynamic infrastructure-less communication network wherever it is required. The nodes in the network not only acts as hosts but also as routers that discover and maintain routes to other nodes in the network. (Fig 1). Quick and easy establishment of such networks make them feasible to be used in military, disaster area recovery and in other environments where no infrastructure exists or it has been destroyed. Since mobile nodes move in various directions causing existing links to break and the establishment of new routes, routing in such networks is a challenging task. The mobility (i.e. how nodes move) of mobile nodes plays a significant role on the performance of routing protocols. Routes between two communicating nodes may consist of multiple hops through other nodes in the network. Therefore, finding and maintaining routes in MANET is nontrivial.

Several routing protocols have been developed for mobile ad hoc networks. Such protocols must deal with typical limitations of these networks which include low bandwidth, high power consumption, and high error rates. Figure 2 shows the categorization of these routing protocols. In table-driven routing protocols, all the nodes need to maintain the routing information in the tables and update it periodically even if they need to communicate or not. In this approach, path finding latency is small but overhead is too high since a path which is not used for a long time is still maintained and updated. Examples include Destination-Sequenced Distance-Vector (DSDV) 
routing [1], Wireless Routing Protocol (WRP) [2], Global State Routing (GSR) [3], and Fisheye State Routing (FSR) [4].

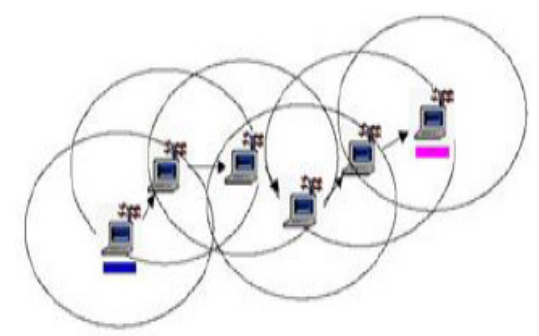

Figure 1. Mobile Ad hoc Network

On the contrary, in on-demand routing protocols, routes are discovered between source and destination pair only when data is to be sent. This provides reduced overhead but high path finding latency as whenever the route is to be found between source and destination, route discovery procedure is initiated. Examples include Ad hoc On-demand Distance Vector Routing (AODV) [5], Dynamic Source Routing (DSR) [6], and Cluster Based Routing protocol (CBRP) [7]. Due to bandwidth constraints, on demand approach (i.e. the route discovery is initiated only if there is a demand for communication) is often used in wireless ad-hoc network scenarios.

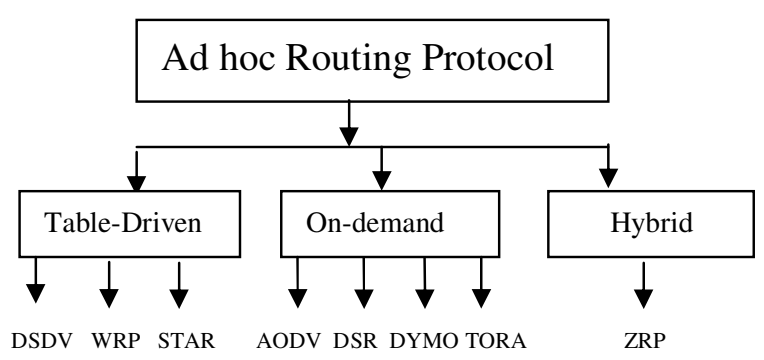

Figure2. Categorization of ad-hoc routing protocol

Hybrid routing protocols combine the merits of both proactive and reactive routing protocols and overcome their shortcomings. Normally, hybrid routing protocols for mobile ad hoc networks exploit hierarchical network architectures. Proper proactive routing approach and reactive routing approach are exploited in different hierarchical levels, respectively. Examples of hybrid routing protocols for mobile ad hoc networks are the Zone Routing Protocol (ZRP) [8], Zone-based Hierarchical Link State routing (ZHLS) [9].

The above mentioned protocols establish and maintain the routes on the best effort basis. Since entertainment and other multimedia services such as audio and video are usually more demanding applications today, so in order to truly realise the potential of MANETs, they must be able to deliver such services, for which best-effort protocols are not adequate [10]. This is because multimedia applications require the underlying network to provide certain guarantees that are manifested in the support of several important Quality of Service (QoS) parameters such as throughput, delay, jitter, packet delivery rate. However, achieving QoS guarantees in MANETs is a challenging task due to the inherent features of MANETs.

The purpose of this paper is to evaluate the best effort proactive and reactive routing protocols DSDV, AODV and DSR on the basis of QoS metrics (packet delivery ratio, average end to end 
delay, throughput, jitter) normalized control overhead, normalized MAC overhead by varying network mobility, node density and network load. Therefore this work can provide motivation for further research on improving the current protocols and/or create new ones to meet the challenges of wireless networks.

The rest of the paper is organized as follows: Section 2 provides the related work in the area of evaluation of routing protocols for mobile ad hoc networks Section 3 presents an overview and the general comparison of the three main ad hoc routing protocols (DSDV, DSR, AODV). The simulation environment and performance metrics are described in Section 4 and then the results are presented in Section 5. Section 6 concludes the paper and presents the future work.

\section{RELATED WORK}

Over recent years, significant work has been conducted to evaluate the performance of routing protocols in ad hoc wireless networks. J. Broch et al. [11] presented performance evaluation studies of multiple routing protocols (DSDV, TORA, DSR, and AODV) through simulations conducted with the ns-2 simulator. They used random waypoint model as a mobility scenario and packet delivery ratio and the routing overhead as the metrics in order to evaluate the performance of the tested protocols. Das et al. [12] carried out the simulation analysis of AODV and DSR. Their simulation has a model of 50 (the first group of experiment) and 100 (the second group of experiment) nodes at varying pause times. In Boukerche [13] the performance evaluation of three routing protocols (AODV, CBRP, and DSR) is presented. The throughput and the average end-toend delay are used as the evaluation metrics for the simulations. Their main finding is that source routing is much more efficient than the distance-vector-based protocols, like AODV. Boukerche [14] suggests that position aware routing protocols, in which nodes are equipped with a GPS device, present better performance and minimize routing overhead. Ahmed and Alam [15] compare three routing protocols (DSR, AODV, and TORA) through simulations conducted with a discrete-event simulator (OPNET Modeler). Simulation results indicate that TORA presents a higher performance than AODV and DSR under specific simulation parameters. In Divecha et al. [16], performance of the protocols (DSR and AODV) has been compared by varying node density and the number of hops. The effect of various mobility models on the performance of these protocols is also studied. The experimental results illustrate that the performance of routing protocols varies across different mobility models, node densities and length of data paths. In Kumar et al. [17], a performance comparison of two prominent on-demand reactive routing protocols (DSR and AODV) and one proactive routing protocol (DSDV) is presented. In Rahman and Zukarnain [18] the performance comparison between three routing protocols, namely AODV, DSDV and an improvement of DSDV, is presented by using three metrics, namely packet delivery ratio, end-to-end delay, and routing overhead in three different scenarios: varying pause time, no of nodes and node speed. Simulation results show that I-DSDV as compared to DSDV, reduces the number of dropped data packets with little increased overhead at higher rates of node mobility but still can't compete with AODV in higher node speed and number of nodes. In Qasim et al. [19], another performance evaluation study is presented. The authors have comprehensively analyzed the results of simulation for OLSR, TORA and AODV routing protocols by using quality of service parameters like end to end delay, media access delay, throughput, packet delivery ratio and routing load. In M.S. Islam et al. [20], a comparative performance analysis of the routing protocols (DSR, AODV, TORA, OLSR, GRP) for supporting video streaming applications is presented. Throughput, wireless LAN delay, end-to-end delay and packet delay variation are considered as the performance metrics. Their simulation results show that TORA has the best overall performance. In Ronald Beaubrun and Badji Molo [21], implementation of an adaptation of DSR is presented. Services constraints such as end-to-end delay, packet delivery ratio and normalized routing load are considered. Simulation results show that DSR performs well with low mobility and low traffic intensity. K. Vats et al.[22] present the performance analysis of 
OLSR routing protocol using OPNET simulator. The simulation is done with 30,40 , and 50 nodes moving randomly in an area of the network range 10,000 sq $\mathrm{m}$. The results show that it has better performance in all aspects in a network.

This paper evaluates the three MANET routing protocols (DSDV, AODV and DSR) based on QoS metrics (packet delivery ratio, average end to end delay, throughput, jitter) normalized control overhead, normalized MAC overhead by varying network mobility, node density and network load.

\section{OVERVIEW OF ROUTING PROTOCOLS}

In this section, a brief overview of the routing operations performed by the familiar protocols DSDV, AODV and DSR are discussed.

\subsection{Destination-Sequenced Distance-Vector (DSDV) Protocol}

The Destination-Sequenced Distance-Vector (DSDV) protocol [1] is a proactive routing algorithm and is an enhanced version of the distributed Bellman-Ford algorithm. Each node maintains a table that contains the shortest distance and the first node on the shortest path to every other node in the network. It incorporates table updates with increasing sequence number tags to find out stale routes and prevent routing loops. For table consistency, routing information is propagated to update routing table periodically. The table updates are of two types: incremental updates and full dumps. Incremental updates carry only the changed routing information since the last full dump process. Full dumps carry all available routing information. Therefore a node exchanges routing tables (fully or partially) with its neighbours, periodically or whenever a change in topology is detected. The protocol has the advantage of lower route request latency, but the disadvantage of higher overhead. The protocol performs best in network with low to moderate mobility and few nodes.

\subsection{Ad Hoc On-demand Distance Vector Routing (AODV) Protocol}

The Ad Hoc On-demand Distance Vector Routing (AODV) protocol is a reactive unicast routing protocol for mobile ad hoc networks [5] in which a route is established only when required by a source node for transmitting data packets. The routing information is maintained in the routing tables at all the nodes. It only needs to maintain the routing information about the active paths. A routing table entry expires after a certain time-out period. When a source node wants to send packets to the destination but no route is available, it initiates a route discovery operation. The source node floods Route Request (RREQ) packets which includes source identifier, the destination identifier, the source sequence number, the destination sequence number, the broadcast identifier and the time to live field. Destination Sequence Number is used to identify the most recent path. When the destination or a node that has a route to the destination receives the RREQ, it checks the destination sequence numbers it currently knows and the one specified in the RREQ. To guarantee the freshness of the routing information, a route reply (RREP) packet is created and forwarded back to the source only if the destination sequence number is equal to or greater than the one specified in RREQ. AODV uses only symmetric links and a RREP follows the reverse path of the respective RREQ. When an intermediate node receives the RREP, it sets up a forward path entry to the destination in its route table. The redundant RREP packets or RREP packets with lower destination sequence number will be dropped. Once the source node receives a RREP it can begin using the route to send data packets. When either destination or intermediate node moves, a route error (RERR) message is sent to the affected source nodes. When source node receives the (RERR) message, it can reinitiate route discovery if the route is 
still desired. The main advantage of this protocol is that routes are established on demand and destination sequence numbers are used to find the latest route to the destination. Also the connection setup delay is less. The disadvantage is more number of control overheads due to many route reply messages for single route request. Another disadvantage is that periodic hello message leads to unnecessary bandwidth consumption.

\subsection{Dynamic Source Routing (DSR) Protocol}

DSR uses source routing and caching [6] where the sender node includes the complete hop-byhop route to the destination node in the packet header and routes are stored in a route cache. When a node wants to communicate with another node to which it does not know the route, it initiates a route discovery process by flooding RouteRequest (RREQ) packets. Each node upon receiving a RREQ packet, rebroadcasts the packet to its neighbours if it has not forwarded already or if the node is not the destination node, provided the packet's time to live counter has not exceeded. Each RREQ carries a sequence number generated by the source node and the path it has traversed. When a node receives a RREQ, it checks the sequence number on the packet before forwarding it. The packet is forwarded only if it is not a duplicate RREQ. The sequence number on the packet is used to prevent loop formations and to avoid multiple transmissions of the same RREQ by an intermediate node that receives it through multiple paths. Thus all the nodes except the destination forward a RREQ packet during the route construction phase. A destination node, after receiving the first RREQ, sends RouteReply(RREP) to the source node. The RREP packet takes the traverse path back to the source node established by the RREQ packet. This route is stored in the source node cache for future communication. If any link of this route is broken, the source node is informed by a Route Error (RERR) packet and this route is discarded from cache. Intermediate nodes store the source route in their cache for possible future use. The advantage of this protocol is that intermediate nodes utilize the route cache information efficiently to reduce the control overhead. The disadvantage of the protocol is that stale route cache information could also result in inconsistencies during the route construction phase. Another is that it may perform poorly in networks with high mobility and heavy traffic loads because of high overhead packets.

A comparison of the characteristics of the above three ad hoc routing protocols DSDV, DSR, AODV is given in following table.

Table1. Property Comparison of DSDV, AODV and DSR

\begin{tabular}{|l|l|l|l|}
\hline Protocol Property & DSDV & AODV & DSR \\
\hline Reactive & No & Yes & Yes \\
\hline Routes maintained in & Route Table & Route Table & No \\
\hline Periodic Broadcast & Yes & Yes & No \\
\hline Loop Free & Yes & Yes & Yes \\
\hline Multicast Routes & No & No & Yes \\
\hline Unidirectional Link Support & No & No & Yes \\
\hline Multicast & No & Yes & No \\
\hline Distributed & Yes & Yes & Yes \\
\hline QoS Support & No & No & No \\
\hline Route Cache/Table Timer & Yes & Yes & Yes \\
\hline
\end{tabular}


International Journal of Computer Networks \& Communications (IJCNC) Vol.6, No.2, March 2014

\section{SIMULATION AND PERFORMANCE METRICS}

The simulations were performed using Network Simulator2 (NS-2) [23], particularly popular in the ad hoc networking community.

\subsection{Simulation Scenario:}

The traffic sources are CBR (continuous bit - rate). The source-destination pairs are spread randomly over the network.The detailed description of simulation environment is presented below in table2.

Table 2. Simulation Parameters

\begin{tabular}{|l|l|}
\hline Parameter & Value \\
\hline Simulator & Ns-2.34 \\
\hline Radio-propagation model & Propagation/Two ray round wave \\
\hline Channel type & Channel/Wireless channel \\
\hline MAC Type & Mac /802.11 \\
\hline Network interface type & Phy/WirelessPhy \\
\hline Interface queue Type & Queue/Drop Tail \\
\hline Link Layer Type & LL \\
\hline Antenna & Antenna/Omni Antenna \\
\hline Maximum packet in ifq & 50 \\
\hline Area ( M*M) & $1000 * 1000$ \\
\hline Number of mobile node & $20-100$ \\
\hline Source Type & CBR(constant bit rate) \\
\hline Simulation Time & $300 \mathrm{~s}$ \\
\hline Routing Protocols & DSDV, AODV and DSR \\
\hline Number of connection & 20 \\
\hline Data rate & $2-20$ packet/second \\
\hline Pause time & 5 second \\
\hline Packet size & 512 \\
\hline Mobility Model & Random Way point model \\
\hline Transmission Range & $250 \mathrm{~m}$ \\
\hline Mobility speed & $0-20 \mathrm{~m} / \mathrm{s}$ \\
\hline
\end{tabular}

\subsection{Performance Metrics:}

The following performance metrics are considered for evaluation:

Packet delivery ratio: Packet Delivery Ratio (PDR) is the ratio between the number of packets transmitted by a traffic source and the number of packets received by a traffic sink. It represents the maximum throughput that the network can achieve. A high packet delivery ratio is desired in a network. 


$$
P D R=\frac{\sum C B R \text { packet received by } C B R \text { destination }}{\sum C B R \text { packet sent by } C B R \text { sources }} \times 100
$$

Average end to end delay: End-to-end delay is the average time delay for data packets to reach from the source node to the destination node. It includes processing, queuing and propagation delay of the link. The performance is better when packet end-to-end delay is low.

$$
\text { Avg. EED }=\frac{1}{N} \sum_{n=1}^{N}\left(T R_{n}-T S_{n}\right)
$$

$T S_{n}=$ Time at which data packet $\mathrm{n}$ was sent

$T R_{n}=$ Time at which data packet $\mathrm{n}$ was received

$\mathrm{N}=$ Total number of data packets received

Throughput: Throughput is the total packets successfully delivered to individual destinations over total time.

$$
\text { Throughput }=\quad \frac{\sum \text { No of packet succeefully received at the CBR destnation }}{\text { Unit time }}
$$

Jitter: Jitter is the delay variation between each received data packets. The variation in the packet arrival time should be minimum to have better performance in Mobile Ad-hoc Networks.

Normalized Routing/Control Overhead: Normalized Routing Overhead is defined as the number of routing packets "transmitted" per data packet "delivered" at destination. The performance is better when routing overhead is low.

$$
N R O=\frac{\sum \text { Routing Control Packets }}{\sum \text { Data Packets Delivered }}
$$

Normalized MAC Overhead: The normalized MAC load is defined as the fraction of all control packets (routing control packets, Clear-to-Send (CTS), Request-to-Send (RTS), Address Resolution Protocol (ARP), requests and replies, and MAC ACKs) over the total number of successfully received data packets. This is the metric for evaluating the effective utilization of the wireless medium for data traffic.

$$
N M O=\frac{\sum M A C \text { Control Packets }}{\sum \text { Data Packets Delivered }}
$$

\section{SIMULATION RESULTS}

The simulation results are shown in the following section in the form of graphs. Graphs show comparison between the three protocols on the basis of the above mentioned metrics by varying mobility speed of the nodes, network size and the network load.

\subsection{Varying the node speed or dynamic property of the network}

In the first set of simulations, the mobility speed of the nodes is varied. The nodes start with a low velocity of $5 \mathrm{~m} / \mathrm{s}(18 \mathrm{~km} / \mathrm{h})$ and then the node velocity increases up to $20 \mathrm{~m} / \mathrm{s}(72 \mathrm{~km} / \mathrm{h})$. The data rate is kept constant at10 packets/s (40.960 kbps) and the no. of nodes and connections are fixed at 50 and 20 respectively. 


\section{Packet Delivery ratio}

Figure 3(a) shows the packet delivery ratio of the protocols AODV, DSR and DSDV. AODV and DSR almost show the similar performance. Packet delivery ratio for the protocols decreases as speed increases. This is because, at higher speeds, link breakage may occur more frequently and therefore a packet loss fraction is increased. Although the packet delivery fraction of all the protocols decreases as speed increases, but DSDV's packet delivery fraction decreases in a more rapid fashion due to its excessive channel usage by regular routing table updates. Furthermore, as mobility speed increases, more event-triggered updates are generated, resulting in even more packet delivery fraction decrease. This problem is not present in AODV, DSR since routes are generated only on-demand.

\section{Average end to end delay}

Figure 3(b) shows the average end to end delay of the three routing protocols. With the increase of movement speed, topology change may occur more frequently and thus the probability of broken links increases. Broken links may cause additional route recovery process and route discovery process. This leads to increase in average end-to-end delay of packets as the node speed increases. AODV protocol performs well for dynamic network than DSR and DSDV on average end to end delay because it adopts both proactive and reactive features. i.e hop by hop and on demand routing features. In DSDV routing protocol, when the route break occurs in the network, the uplink and downlink nodes generate hello packets after waiting for the hello interval and thus hello packets are propagated in the network with some delay (propagation delay). Moreover some processing delay is also created due to the exchange and the updates of the routing tables at the nodes. Both these processing and the propagation delays are responsible for the increased end to end delay in case of DSDV. DSR end to end delay increases at high mobility speed because it suffers from stale route cache problem. Also DSR is source path routing and when mobility is more in the network, less number of route replies are successfully received by the CBR sources.

\section{Throughput}

Again in the fig 3(c), the throughput of AODV and DSR is more than DSDV because when the mobility speed of the node is increased, throughput of DSDV decreases more as the node is busy in updating its routing table. DSR and AODV throughput is also decreased but its value is nominal.

\section{Jitter}

Figure 3(d) shows the delay jitter of the three routing protocols. Jitter is dependent on delay as in jitter, variation of the packet arrival time is calculated in the network on the receiver side. That's why the jitter is almost in the same fashion for all the protocols like delay. DSR has lower jitter on less speed because it utilizes the route information stored in the route cache for creating the connection but has more jitter variation above $10 \mathrm{~m} / \mathrm{s}$ because at higher speeds, the DSR node cache information is stale for the other nodes.

\section{Normalized Routing Overhead}

Figure 3(e) shows the normalized routing load. DSDV has the best performance with an increase of the routing load at a higher mobility. AODV routing overhead is more than DSR and DSDV because it generates more no. of control packets to find a fresh enough route to destination node. It increases when nodes move at higher speeds. DSR has higher routing load than DSDV due to its source path routing and stale route cache problem at increased mobility. But actually the 
International Journal of Computer Networks \& Communications (IJCNC) Vol.6, No.2, March 2014

control overhead is measured based on the size of control packets in terms of bytes in the network. Size of control packets (in bytes) generated by DSDV and DSR protocols is greater than AODV protocol and when the size of the control packets increases, then the packets need to be fragmented, and it is difficult to handle fragmented packets in the mobile ad hoc network. That's why DSR is not suitable for big ad hoc network. From this observation, it can be concluded that AODV protocol is best suitable for the dynamic network.

\section{Normalized MAC overhead}

Figure 3(f) shows the normalized MAC overhead. AODV has higher normalized MAC load than DSR. DSDV is the most stable protocol in terms of the normalized MAC load in networks with varying mobility.

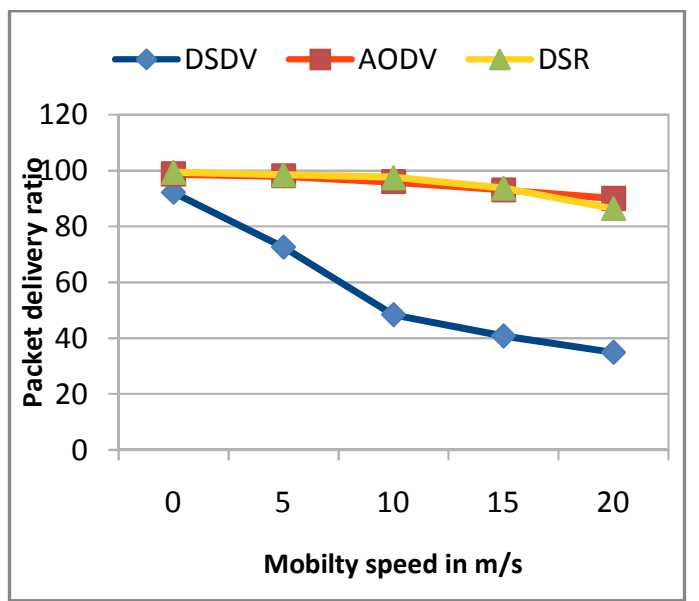

(a)

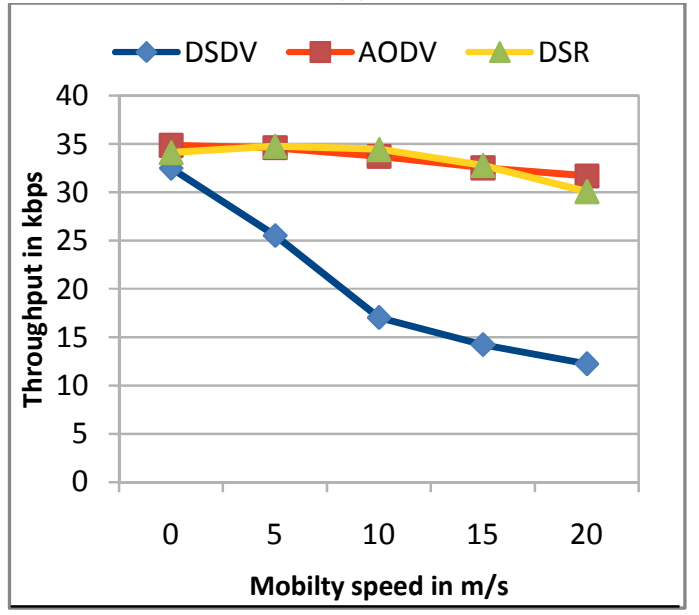

(c)

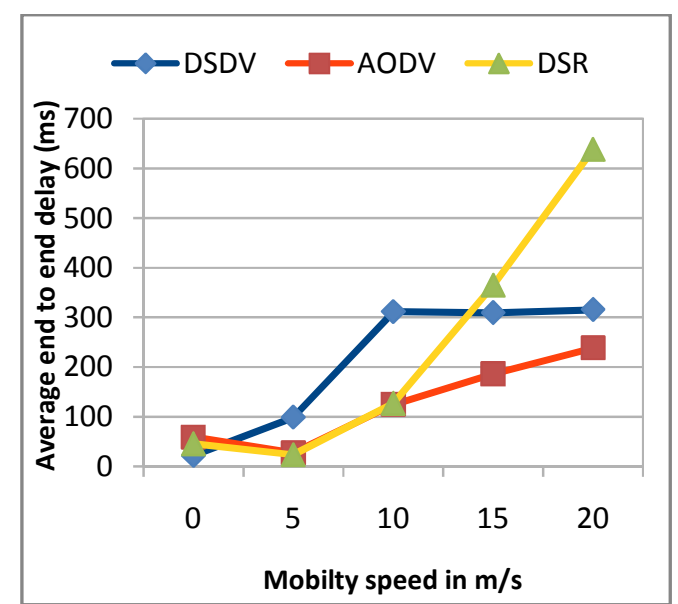

(b)

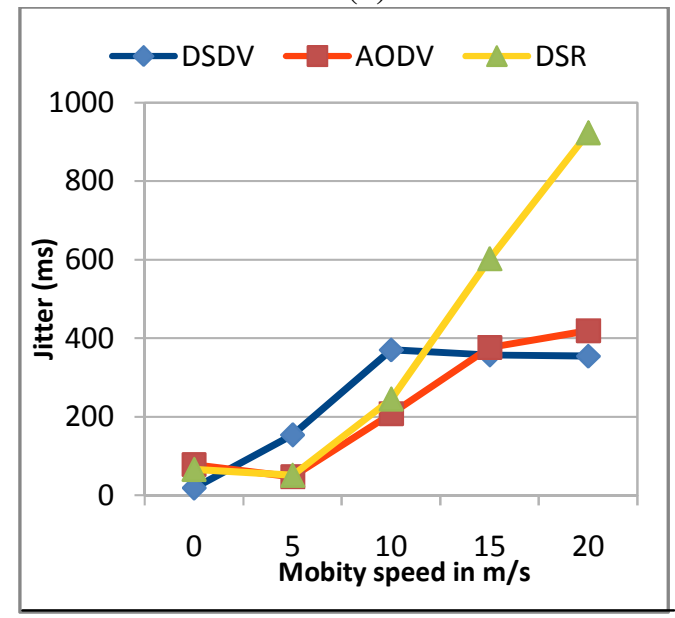

(d) 
International Journal of Computer Networks \& Communications (IJCNC) Vol.6, No.2, March 2014

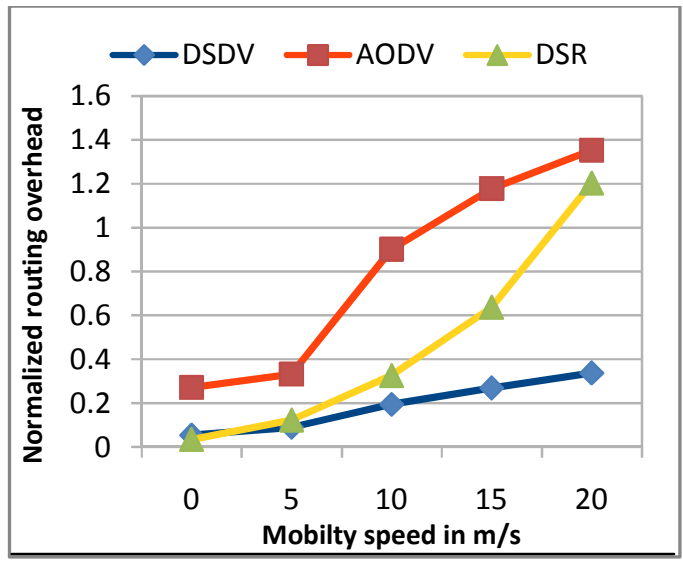

(e)

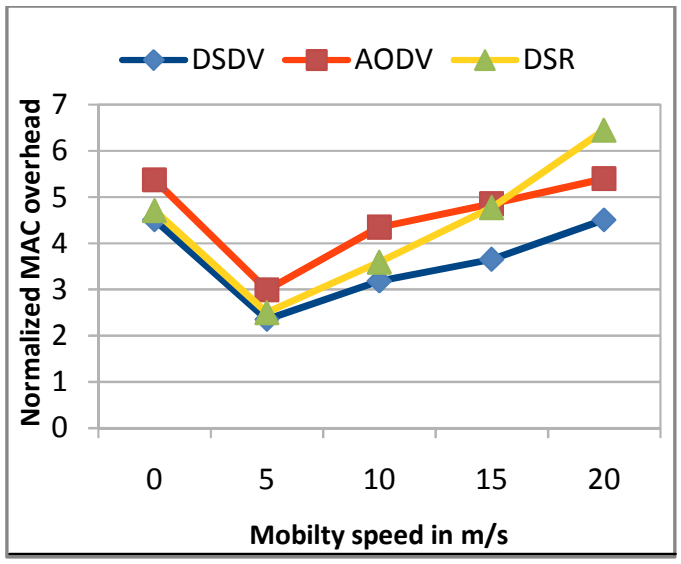

(f)

Figure 3. Varying Network Mobility

\subsection{Varying the network size or density}

In the second set of the simulations, the numbers of nodes are varied in the network. The objective is to analyse the impact of node density on the protocol's performance. A desirable property of a protocol is to have stable behaviour regardless of the number of nodes in the network. The no. of nodes is gradually increased in the network and takes the values $20,40,60,80$ and 100 . The mobility speed has the range $3-7 \mathrm{~m} / \mathrm{s}$, and the packet rate, no. of connections are fixed at 10 packet/sec and 20 respectively. Other parameters remain fixed for the evaluation of the AODV, DSR and DSDV routing protocols for mobile ad hoc networks.

\section{Packet Delivery Ratio (PDR)}

In fig 4(a), AODV and DSR have almost the same packet delivery ratio while DSDV packet delivery ratio is quite low as compared to reactive protocols because in DSDV, a node maintains route for all the nodes available in the network. When the numbers of nodes are increased, DSDV node overhead will also increase. It increases processing delay. Due to this increased processing delay, large no. of data packets are dropped at the node queue. It also happens that DSDV maintains route with more hop count than AODV and DSR because it maintains route in proactive manner. That's why DSDV PDR is deceased when we increase the number of node from 80 to 100 .

\section{Average End to End Delay}

In fig 4(b), DSDV has higher end to end delay due to it's proactive features. DSR often uses stale routes due to the large route cache, which leads to frequent packet retransmission and high delay times. AODV uses the source-initiated approach in the route discovery process, and table-driven approach in the route maintenance stage, due to which it shows the better delay characteristics.

\section{Throughput}

Figure 4(c) shows that AODV and DSR throughput is almost equal and is better than DSDV because they have higher packet delivery ratio than DSDV. The relatively lower throughput for DSDV is caused by packets that are sent (and lost) before routes have converged initially in the network. 


\section{Jitter}

In fig 4(d), AODV shows the smallest rising slope and also displays the most superior jitter performance. Combined with fig 4(a) it can also be seen that its packet delivery ratio is highest which shows that AODV protocol is stable and reliable. DSR has higher jitter initially because DSR is the source path routing so finding the path from the source to the destination is more complex and has more overhead in the network (because size of the control packet is more). Also the source node requires to put the complete route information in the data packet every time before sending to the destination, so node processing delay is increased which increases the jitter value. But this jitter decreases when the number of nodes increases. DSDV has more end to end delay than two protocols that's why DSDV has more jitter variation.

\section{Normalized Routing Overhead}

Figure 4(e) shows the normalized routing load. DSR has the lowest normalized routing load. Due to aggressive caching, DSR most often finds a route in its cache and therefore rarely initiate a route discovery process unlike AODV. But because these routes are most often stale routes, a lot of packets get dropped. DSR's routing overhead is dominated by route replies (unicast packets), while AODV's routing load is dominated by route requests (broadcast packets). Therefore, DSR performs well when looking at the routing overhead. AODV has a higher normalized routing load than DSR and DSDV because of its request broadcasting. When the number of node increases, the request propagation also increases. Also AODV uses HELLO message to confirm the connectivity of each pair of nodes which leads to bigger overhead than DSDV.

\section{Normalized MAC overhead}

Figure 4(f) reveals that DSDV have lowest MAC overhead which shows that it has lower congestion at MAC layer and that too occurs due to control packet generated in the network layer. While in AODV, the MAC overhead is high which reveals that packet are dropped due to contention.

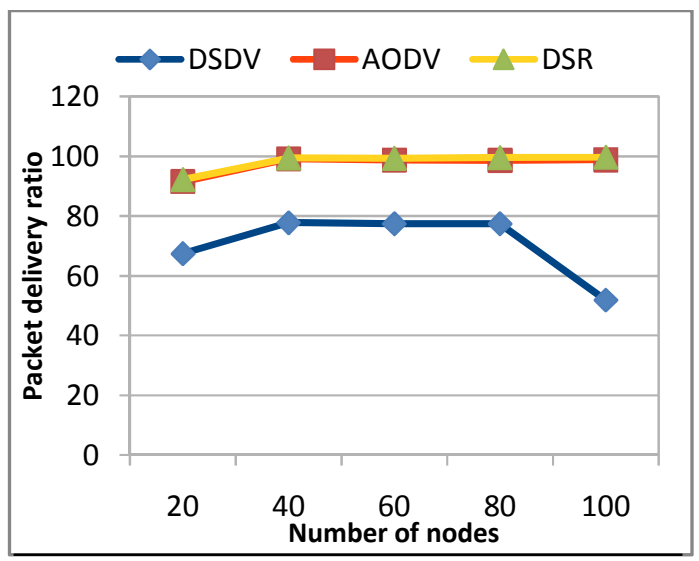

(a)

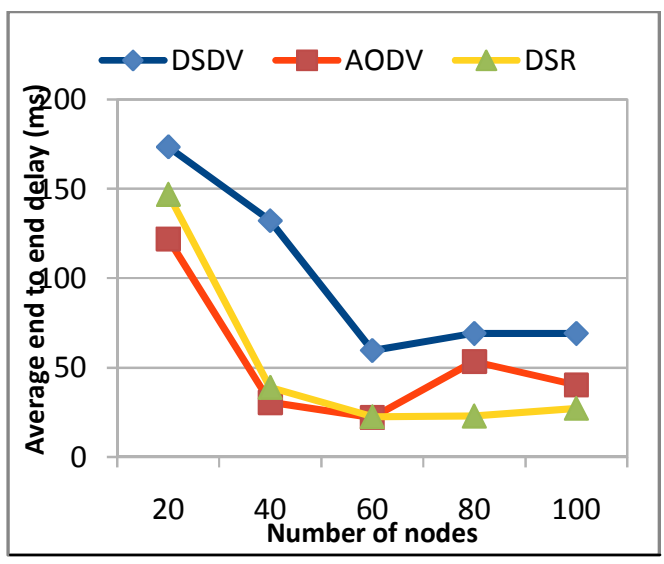

(b) 


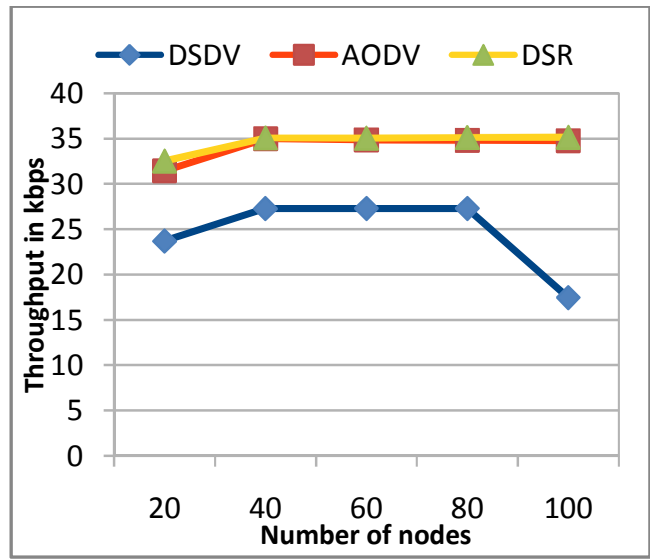

(c)

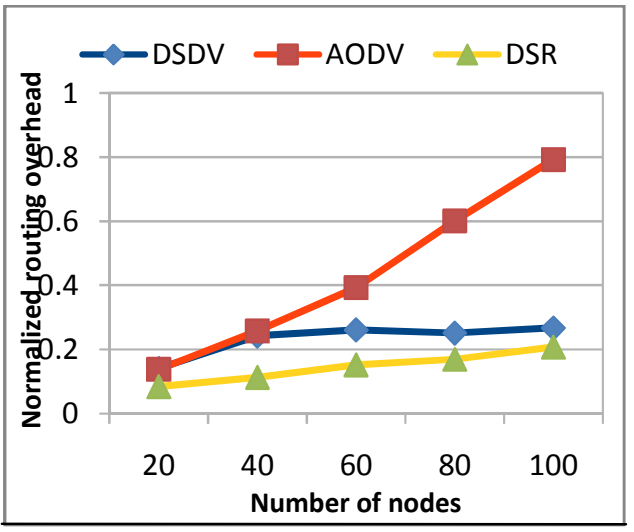

(e)

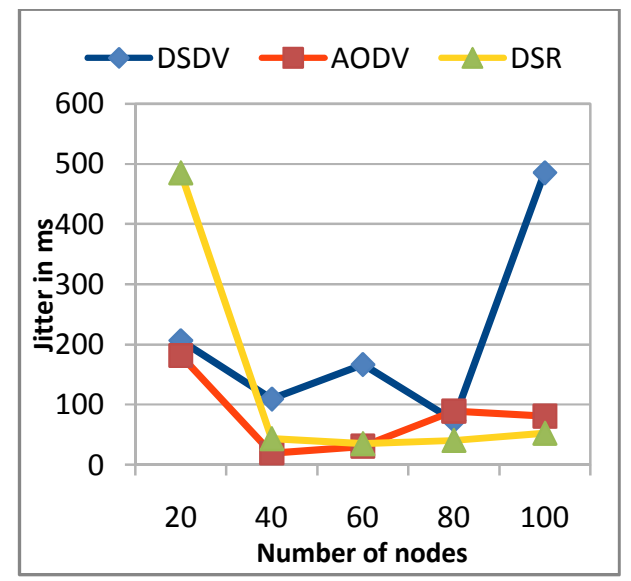

(d)

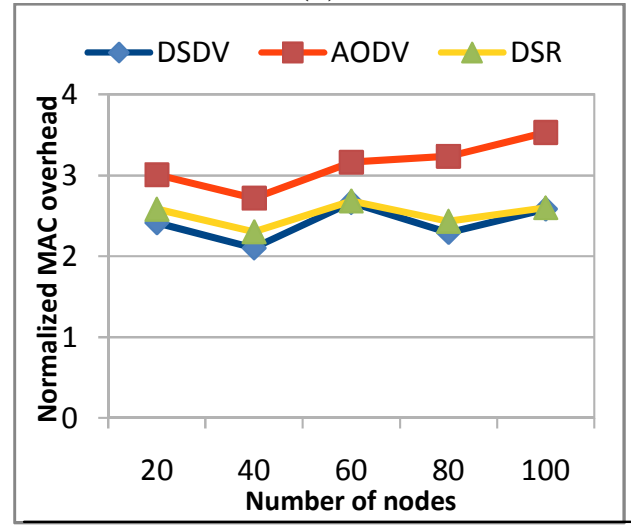

(f)

Figure 4. varying the network size

\subsection{Varying the network load}

In the final set of simulations, the number of data packets sent by the sources is increased from 5 packets/s (20.480 kbps) to 20 packets/s $(81.920 \mathrm{kbps})$. The mobility speed has the range $3-7 \mathrm{~m} / \mathrm{s}$, no. of nodes and the connections are fixed at 50 and 20 respectively. The other parameters remain the same.

\section{Packet Delivery ratio}

Figure 5(a) shows the packet delivery ratio of the three protocols where DSR has the highest packet delivery ratio while varying the load. This is because it utilizes the path from route cache and also the processing time is very less than communication time (sends more number of packets with added route information). Above the 12 packet/sec, the packet delivery ratio of all the protocols decreases due to more data load on the network. However, it can be observed that data packets are dropped by AODV for the following reason: in AODV, the source node sends RREQ message only if the route to the destination node does not exist. After the second transmission of the RREQ message, if the source node does not receive a RREP message within the time interval, it will drop the first packet in the queue and repeat the same procedure for the second data packet in the queue. However, when any intermediate node cannot find a valid route to the destination node by repeating the above procedure, it will drop not only the first packet but also all data packets from its queue, thereby degrading the protocol's performance. 


\section{Average end to end delay}

In fig. 5(b), DSDV outperforms DSR and AODV in terms of delay metrics for the increased load in the network. DSDV is proactive routing protocol so it has route to the destination all the time. That's why, when the data rate of node is less, it utilizes the route which is available in the node routing table. When the data rate of the node is increased above 8 packets per second, the cbr packets available in the network are more so congestion occurs which causes the packets to wait in the node for the processing. This queuing delay ultimately affects the end to end delay of the network that's why DSDV end to end delay has increased for the data rate above 8 packet/s. Reactive routing protocols AODV and DSR have more end to end delay than DSDV. They find the path when the node requires to communicate with the destination. Initially, the data rate is less and the control packets are more, so they do not utilize the path efficiently which results in increased delay. But when the rate increases, the congestion in the network also increases which results in increased delay. AODV delay is less as compared to DSR because DSR inserts the complete route information in the application packet so the processing delay increases. AODV and DSR performance is almost equal for the data rate of 8 packet/s.

\section{Throughput}

In fig 5(c) AODV and DSR have better throughput than DSDV because these are the reactive protocols and utilize the path information available in the routing table (route cache in case of DSR) and when the data rate increases, no. of CBR packets increases, congestion increases and these reactive routing protocols route to the destination fastly than DSDV protocol.

\section{Jitter}

In fig 5(d), AODV outperforms DSR and DSDV protocol in terms of jitter variation for the increased load in the network because it uses features of both DSDV and DSR routing protocol. DSDV initially has lower jitter than the two protocols because in the network, less no of data packets are available and it utilizes the path information available in the node routing table but when data rate of the node is increased to 12 packet/s or more, congestion increases, more number of packet are dropped and thus the jitter increases. DSDV generates the routing message only after waiting for the hello interval, while in case of reactive protocols, when the network load increases, jitter reduces because they generate the routing messages whenever the route to the destination is invalid (and do not wait for hello interval). DSR has more jitter for the reason described above in case of performance of delay metric.

\section{Normalized Routing Overhead}

In fig 5(e), DSDV has the best performance with an increase of the routing load at a higher mobility. DSR shows lower routing load than AODV as due to aggressive caching, DSR most often finds a route in its cache and therefore rarely initiate a route discovery process unlike AODV. DSR's routing overhead is dominated by route replies (unicast packets), while AODV's routing load is dominated by route requests (broadcast packets). Therefore, DSR performs better than AODV in terms of routing overhead.

\section{Normalized MAC overhead}

Figure 5(f) shows the normalized MAC load. DSDV again presents the lowest MAC load and AODV has the highest MAC load at lower data packet rates, which drops when the data rates increases. 
International Journal of Computer Networks \& Communications (IJCNC) Vol.6, No.2, March 2014

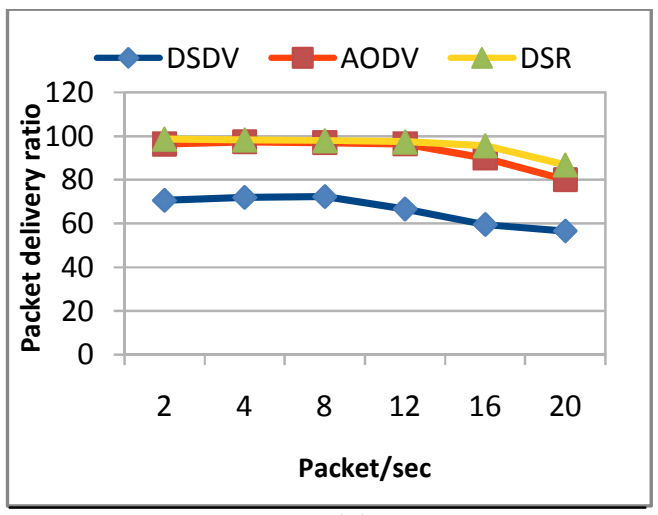

(a)

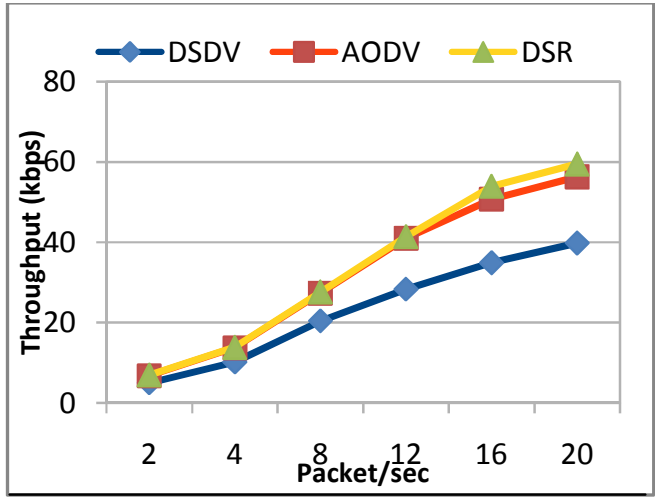

(c)

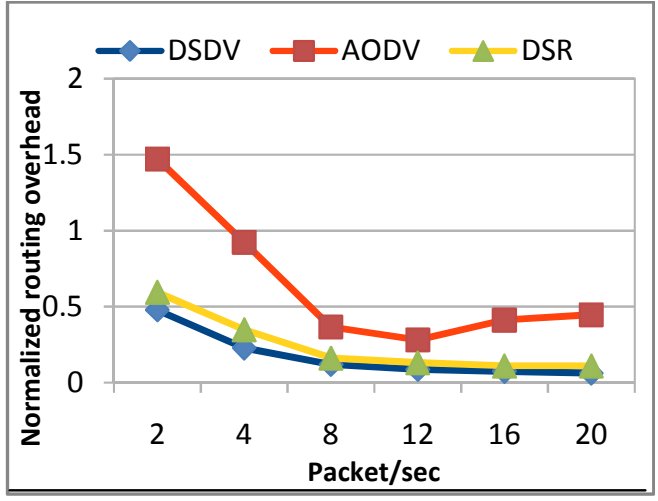

(e)

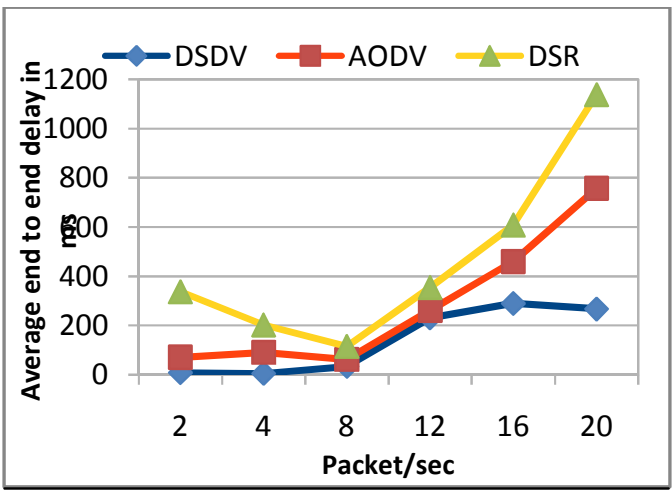

(b)

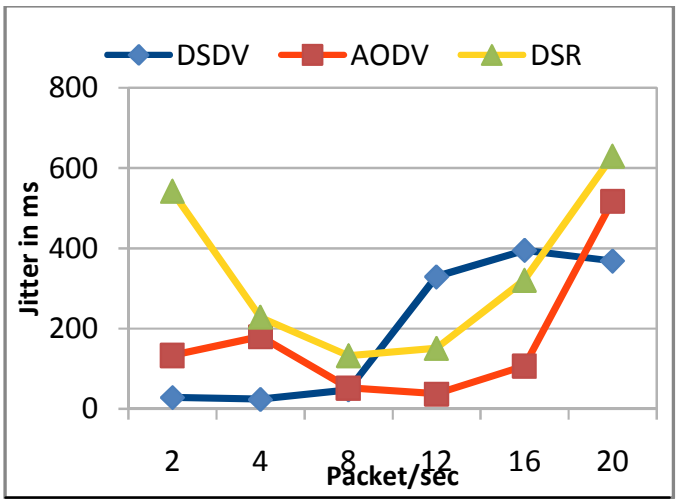

(d)

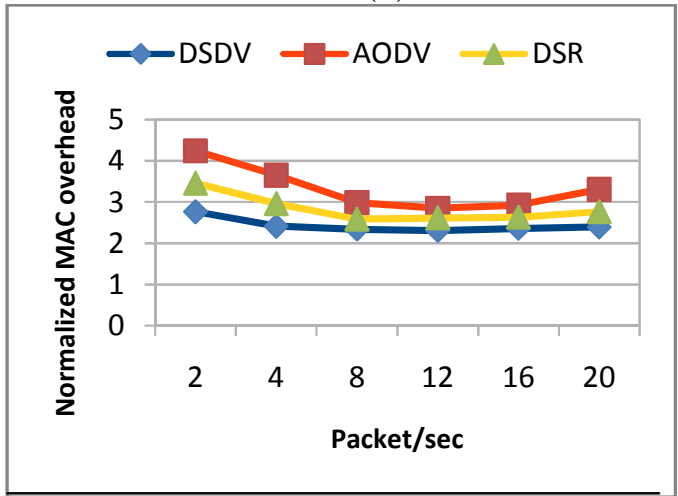

(f)

Figure 5 varying network load

\section{CONCLUSIONS}

As it can be seen, there are large number of different kinds of routing protocols in mobile ad-hoc networks, the use of a particular routing protocol in mobile ad-hoc network depends upon the factors like size of the network, load, mobility requirements etc. This paper compares the performance of DSDV, AODV and DSR routing protocols for mobile ad hoc networks using NS2 simulator.

The routing protocols have been compared on the basis of QoS metrics (packet delivery ratio, average end-to-end delay, throughput, jitter) normalized routing load and normalized MAC load 
by varying mobility speed of the nodes, network size and the network load. Simulation results show that DSDV is a proactive routing protocol and is suitable for limited number of nodes with low mobility due to the storage of routing information in the routing table at each node. Since DSR protocol uses source routing and route cache, byte overhead in each packet will increase whenever network topology changes. Hence, DSR is preferable for moderate traffic with moderate mobility. For robust scenario where mobility is high, nodes are dense, the amount of traffic is more, AODV performs better among all studied routing protocols. Thus from the simulation results, it can be concluded that for all types of networks, AODV performs optimally well not the best. Though there are some disadvantages of this protocol, it is robust for use in mobile ad hoc networks. Our future work will include the modification to the basic AODV routing protocol so as to make it efficient in providing QoS and meet the challenges of mobile ad hoc networks.

\section{ACKNOWLEDGMENTS}

The authors would like to thank Punjab Technical University, Kapurthala, Punjab, India for the constant support during the research. The authors would also extend gratitude to their family members and friends for their unstinted support throughout this research work.

\section{REFERENCES}

[1] C. E. Perkins and P. Bhagwat, " Highly Dynamic Destination- Sequenced Distance-Vector Routing (DSDV) for Mobile Computers," in Proceedings of ACM SIGCOMM, pp. 234-244, 1994.

[2] S. Murthy and J.J. Garcia-Luna-Aceves, "An efficient routing protocol for wireless networks," ACM Mobile Networks and Applications Journal, pp.183-197, 1996.

[3] T . Chen and M. Gerla, "Global state routing: A new routing scheme for ad hoc wireless networks," in Proceedings of IEEE ICC'98, Vol. 1, pp.171-175, 7-11 June 1998.

[4] A. Iwata, C.-C. Chiang, G. Pei, M. Gerla, and T.-W. Chen, "Scalable Routing Strategies for Ad Hoc Wireless Networks," IEEE Journal on Selected Areas in communications, Special Issue on Ad-Hoc Networks, pp.1369-79, Aug 1999.

[5] C. E. Perkins, B. Royer and S.R. Das, "Ad hoc On Demand Distance Vector (AODV) Routing," http://www.ietf.org/internet-drafts/draft-ietf-manet-aodv-13.txt, IETF Internet draft, Feb2003.

[6] D. Johnson, D.A. Maltz and J. Broch, "The Dynamic Source Routing Protocol for Mobile Ad hoc Networks,"http://www.ietf.org/internet-drafts/draft-ietf-manet-dsr-10.txt, IETF Internet draft, 19 July2004.

[7] M. Jiang, J. Li, Y.C. Tay, "Cluster Based Routing Protocol," August 1999 IETF Draft.http://www.ietf.org/internet-drafts/draft-ietf-manet-cbrp-pec-01.txt.

[8] Z. J. Haas, "The Zone Routing Protocol (ZRP) for ad hoc networks," Internet Draft, Nov. 1997.

[9] M. Joa-Ng and I-Tai Lu, “ A peer-to-peer zone-based two- level link state routing for mobile ad hoc net-works," IEEE on Selected Areas in Communications, Vol. 17, No. 8, pp. 1415- 1425,1999.

[10] M. K. Gulati and K. Kumar, "QoS routing protocols for mobile ad hoc networks: a survey," International Journal of Wireless and Mobile Computing (IJWMC), Vol.5, No.2, pp.107-118, May 2012.

[11] J. Broch, D. Maltz, D. B. Johnson, Y-C.Hu and J. Jetcheva, “ A performance comparison of multihop wireless ad hoc network routing protocols," In Proceedings of the 4th Annual ACM/IEEE International Conference on Mobile Computing and Networking, MobiCom '98, Dallas, TX, 1998.

[12] S.R. Das, C. E. Perkins and E. M. Royer, "Performance comparison of two on-demand routing protocols for ad hoc networks," in Proceedings of the IEEE Conference on Computer Communications (INFOCOM), Tel Aviv, Israel, pp.3-12, March 2000.

[13] A. Boukerche," A performance comparison of routing protocols for ad hoc networks," In proceedings of the 15th International Parallel and Distributed Processing Symposium, SanFrancisco, CA, 2001. 
[14] A. Boukerche, "Performance evaluation of routing protocols for ad hoc wireless networks," Mobile Networks and Applications, Vol.9, No.4, pp.333-342, 2004.

[15] S. Ahmed and M.S. Alam, "Performance evaluation of important ad hoc network protocols,"EURASIP Journal on Wireless Communications and Networking, Vol.2, pp. 42-42, 2006.

[16] A. Divecha, A.C Grosan and S. Sanya , “Impact of node mobility on MANET routing protocols models" Journal of Digital Information Management, Vol.5, pp.19-23, 2007.

[17] B.R.A. Kumar, L.C. Reddy and P.S. Hiremath, " Performance comparison of wireless mobile ad-hoc network routing protocols," International Journal of Computer Science and Network Security, Vol. 8, No.6, pp. 337-343, 2008.

[18] A.H.A Rahman and Z.A. Zukarnain, "Performance comparison of AODV, DSDV and I-DSDV routing protocols in mobile ad hoc networks," European Journal of Scientific Research, Vol.31, No.4, pp.566-576, 2009.

[19] N. Qasim, F. Said and H. Aghvami, “ Mobile ad hoc networking protocols evaluation through simulation for quality of service," IAENG International Journal of Computer Science , Vol.36, No.1, pp.76-84, 2009.

[20] M.S. Islam, A.Riaz and M.Tarique, "Performance Analysis of the Routing Protocols for Video Streaming Over Mobile Ad Hoc Networks" International Journal of Computer Networks \& Communication (IJCNC), Volume 4, Issue 3, pp. 133-150, 2012.

[21] R. Beaubrun and B. Molo, "Using DSR for routing multimedia traffic in MANETs," International Journal of Computer Networks and Communications (IJCNC), Vol.2, No.1, pp. 120-138, January 2010.

[22] K. Vats, M. Sachdeva, K. Saluja and A. Rathee, "Simulation and performance analysis of OLSR routing protocol using OPNET," International Journal of Advanced Research in Computer Science and Software Engineering, Vol. 2, No. 2, February 2012.

[23] K. Fall and K. Vardhan, The Network Simulator (ns- 2).Available:http://www.isi.edu/nsnam/ns

\section{Authors}

Mandeep Kaur Gulati has done B.Tech Electronics \& Electrical Engineering from Guru Nanak Dev Engineering College, Ludhiana, Punjab, India in 1997. She completed her M.Tech (IT) from Guru Nanak Dev University, Amritsar, Punjab in 2004. At present, she is pursuing Ph.D from Punjab Technical University, Kapurthala (Punjab)-India. She has 13 years of teaching experience. Currently she is working as an Assistant Professor in Department of Computer Science at Khalsa College for Women, Amritsar, Punjab, India. Her current research interests include Quality of Service Routing in Mobile Ad hoc Networks.

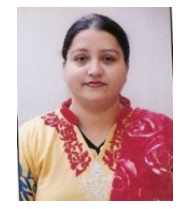

Krishan Kumar has done B.Tech. Computer Science and Engineering from National Institute of Technology NIT, Hamirpur in 1995. He finished his MS Software Systems from BITS Pilani in 2001. He finished his Ph.D from Department of Electronics \& Computer Engineering at Indian Institute of Technology, Roorkee in Feb 2008. Currently, he is an Associate Professor at SBS State Technical Campus, Ferozepur, Punjab, India. His general research interests are in the areas of Information Security and Computer Networks.

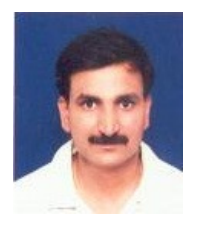
Specific research interests include Intrusion Detection, Protection from Internet Attacks, Web Performance, Network Architecture/Protocols, and Network Measurement/ Modeling. 